\title{
POLÍTICAS DE SAÚDE COLETIVA E GESTÃO URBANA DE RESÍDUOS SÓLIDOS NA FRONTEIRA: UM ESTUDO DE CASO EM PORTO MURTINHO - MS
}

\author{
PUBLIC POLICES OF COLECTIVE HEALTH AND URBAN SOLID \\ WASTE MANAGEMENT IN THE BORDER: CASE OF PORTO \\ MURTINHO - MS
}

Caio Luis Chiariello ${ }^{1}$

\begin{abstract}
RESUMO: O presente estudo tem por objetivo analisar a gestăo dos resíduos sólidos e a sua contribuiçăo para a saúde coletiva da populaçăo próxima ao lixăo do Município de Porto Murtinho - MS. Para tanto partiu da seguinte problemática: a atual gestāo dos resíduos sólidos urbanos do Município de Porto Murtinho - MS contribui com a saúde coletiva de sua populaçấo dos moradores próxima ao lixăo? O estudo partiu de uma abordagem qualitativa, utilizando da pesquisa aplicada, do tipo exploratório - descritivo. Os dados foram coletados por meio de entrevistas semiestruturadas com moradores da regiăo. Os moradores foram selecionados por meio da amostra náo probabilística do tipo intencional, sendo escolhidos 10 (dez) moradores, ou seja, 7,69\% da populaçăo alvo. Analisados os resultados, concluiu-se que os moradores residentes próximos ao lixâo municipal nâo percebem uma boa gestăo dos resíduos por parte do poder público, pois relatam a falta de infraestrutura adequada, condiçôes insalubres e vulnerabilidade para contágios de doenças, tendo em vista a proximidade do lixăo.
\end{abstract}

PALAVRAS-CHAVE: Gestāo urbana. Resíduos sólidos. Políticas públicas municipais.

ABSTRACT: This study aims to analyze the management of solid waste and its contribution to the collective health of the population near the landfill in the municipality of Porto MurtinhoMS for both departed the following problem: the current municipal solid waste management of the municipality of Porto Murtinho-MS contributes to the collective health of its population of residents near the landfill? The study came from a qualitative approach, using the applied research, exploratory-descriptive type. The data were collected through semi-structured interviews with residents of the region. Residents are selected by means of non-probability sample of intentional type, being chosen 10 (ten) residents, i.e. 7.69\% of the target population. Analyzed the results, it was concluded that the residents residing near the city dump just don't

1 Economista (UNESP), Mestre e Doutor em Engenharia de Produçăo (UFSCAR). Professor da FACE da UFGD e Pró-reitor de Gestăo de Pessoas (PROGESP) caiochiariello@ufgd.edu.br 
get a good waste management on the part of the Government, because the lack of adequate infrastructure report, unsanitary conditions and vulnerability to infection of diseases, in view of the proximity of the landfill.

Keywords: Urban solid waste management. Public municpal policies.

\section{INTRODUÇÃO}

O meio ambiente e a sustentabilidade sâo temáticas que ultimamente vem chamando atençấo de todos os atores relevantes para a reflexâo acerca das políticas públicas necessárias para a preservaçăo ambiental concomitante com o desenvolvimento econômico e social. Nesta seara, sâo especialmente os entes públicos os responsâveis pelo monitoramento do compasso entre as atividades produtivas que poderăo gerar impactos positivos e negativos no âmbito da sustentabilidade.

A importância de discutir o meio ambiente e a sustentabilidade em diversas áreas é medida que propicia um alinhamento de estratégias em dois polos convergentes, primeiramente para minimizar os impactos causados pelo homem e segundo, para proporcionar saúde e qualidade de vida a todos.

Neste contexto, discutir a saúde coletiva e meio ambiente é propiciar que os ditames da Constituiçăo Federal de 1988, bem como as de Direitos Humanos sejam atendidos, visando a promoçăo da saúde entre todos. Segundo a OMS (Organizaçăo Mundial da Saúde) assim definiu a saúde ambiental como sendo "o campo de atuaçâo da saúde pública que se ocupa das formas de vida, das substâncias e das condiçóes em torno do ser humano, que podem exercer alguma influência sobre a sua saúde e o seu bem-estar" (FERREIRA e ANJOS, 2001).

Nâo obstante, um ambiente que nâo propicia condiçōes necessárias à manutençâo da vida, será aquele que propiciará a sua destruiçăo (SIQUEIRA e MORAES, 2009). Dessa forma, um dos problemas ambientais gravíssimos que ainda se encontra sem soluçăo năo só no Brasil, mas também em toda a América Latina é a questăo da gestăo dos resíduos sólidos urbanos.

Muitos municípios no Brasil tem sérias dificuldades em resolver os problemas ambientais do destino final de seus resíduos sólidos, devido às questóes de recursos financeiros ou por falta de interesse de seus gestores em buscar parcerias ou convênios (Silva, 2014). A soluçăo para este problema ambiental é de responsabilidade do Estado, como prevê Constituiçấo Federal de 1.988 em seu artigo 23, inciso VI, como competência comum da Uniấo, dos Estados, do Distrito Federal e dos Municípios: "proteger o meio ambiente e combater a poluiçăo em qualquer de suas formas" (BRASIL, 1988).

Vale ressaltar ainda que a Lei Federal nº 12.305/2010 (Política Nacional de Resíduos Sólidos - PNRS) estabelece em seu art. $8^{\circ}$ diversos instrumentos para que o ente alcance os objetivos da política, assim "os planos de resíduos sólidos sâo um dos principais e mais importantes instrumentos, podendo ser elaborados a nível nacional, estadual, microrregional, de regiôes metropolitanas ou aglomeraçóes urbanas, intermunicipal, municipal" (BRASIL, 2016). 
Năo é o que se verifica a fora pelos territórios brasileiros. Segundo Ferreira e Anjos (2001) diversos autores manifestaram a preocupaçăo sobre o assunto da destinaçáo final dos resíduos sólidos no meio ambiente e sua relaçăo com a saúde humana, dentre eles desatacam: (Accurio et al., 1998; Anjos et al., 1995; Cantanhede, 1997; Diaz et al., 1997; Ferreira, 1997; Leite \& Lopes, 2000; Maglio, 2000; Robazzi et al., 1992; Velloso, 1995; Zepeda, 1995), que apontam "as deficiências nos sistemas de coleta e disposiçấo final e a ausência de uma política de proteçâo à saúde do trabalhador, como os principais fatores geradores desses efeitos".

No Município de Porto Murtinho - MS, segundo pesquisa realizada por Silva (2014) “assim como vários do território brasileiro ainda năo conseguiu resolver os problemas ambientais do destino final de seus resíduos sólidos. Pela lei 12.305, sancionada em 2010, todos os municípios deveriam adaptar-se à Política Nacional de Resíduos Sólidos - PNRS o que năo ocorreu".

O presente estudo busca responder a seguinte questăo: a atual gestăo dos resíduos sólidos urbanos do Município de Porto Murtinho - MS contribui com a saúde coletiva de sua populaçăo que residem próximas ao lixăo? Para tanto, o objetivo geral consiste em analisar a gestâo urbana de resíduos sólidos no Município de Porto Murtinho - MS, de acordo com as diretrizes instituídas na Política Nacional de Resíduos Sólidos (PNRS) e suas contribuiçóes para a saúde coletiva da populaçăo residente nas áreas próximas ao lixáo.

Para alcance dos objetivos maiores, estabelece os objetivos específicos para a busca de resposta para a questăo norteadora, sendo: (1) Discutir a importância da gestăo dos resíduos sólidos urbanos para a saúde coletiva, (2) Analisar as políticas públicas de gestâo de resíduos sólidos urbanos e sua relaçăo com a saúde coletiva da populaçăo residente nas áreas próximas ao lixăo, propondo sugestōes de melhorias.

Justifica a realizaçăo desta pesquisa, primeiramente pela importância da contribuiçâo na saúde coletiva da perfeita gestáo dos resíduos sólidos urbanos. Segundo pela qualidade de vida na saúde da comunidade loca do Município de Porto Murtinho - MS, pois o local onde está sendo depositado o lixo, no caso em um terreno, deixados a céu aberto, sem qualquer tipo de seleçăo, limpeza, ou processos adequados para que os lixos năo comprometam aquela área e consequentemente toda a regiăo, ocasionando problemas principalmente no Rio Amonguijá que e um dos afluentes do Rio Paraguai onde feita captaçâo da água para abastecimento da cidade, ocorre à contaminaçáo da terra e com certeza atingir as águas subterrâneas, que estăo sendo consideradas como alternativa pela escassez das águas doces na superfície. Com isso causando doenças por contaminaçấo da água. Além disso, produz diversas substâncias e odores que criam animais causadores de doenças, como por exemplo, ratos, mosquitos, baratas e outros ainda que causem a leptospirose e a dengue.

Assim, o estudo parte de uma pesquisa de abordagem qualitativa, do tipo exploratório e descritivo, a partir de entrevista realizada com moradores dos bairros de Porto Murtinho - MS, que ficam próximas ao lixáo. A seleçáo dos entrevistados foi baseada em amostra năo probabilística năo intencional, em virtude de reconhecer que os mesmos sofrem maiores impactos sobre a gestăo de resíduos e sua relaçâo com a saúde. 


\section{REFERENCIAL TEÓRICO}

\subsection{A SAÚDE COLETIVA}

O direito à saúde está garantido pela Constituiçấo Federal de 1988, no seu artigo 196, sendo um direito de todos e dever do Estado a sua garantia, mediante políticas sociais e econômicas que busquem reduzir os riscos de doenças e outros agravos, preservando acima de tudo, os princípios de acesso universal e igualitário sob as açôes e serviços para a sua promoçăo e recuperaçăo (BRASIL, 1988).

Neste sentido, o Estado deve propiciar mecanismos e políticas públicas para assegurar que este direito fundamental năo seja violado. Segundo Ferreira e Anjos (2001) a boa gestăo dos resíduos sólidos está intrinsecamente correlacionado com a saúde coletiva e seus efeitos e impactos sáo melhores vistos naquelas pessoas que trabalham diretamente com a limpeza urbana, como os catadores de lixo.

De acordo com Siqueira e Moraes (2009) nesta busca de desenvolvimento, o conceito de saúde passa assim a nâo ser abstrata, enraizando no contexto histórico da sociedade, englobando assim as condiçóes de alimentaçăo, habitaçăo, educaçăo, renda, meio ambiente, trabalho, emprego, lazer, a posse de terra e o principal que é o acesso aos serviços de saúde.

Em que pese "a discussáo das questōes ambientais vem ocorrendo de forma paralela ao desenvolvimento da saúde coletiva, sem a necessária articulaçáo que possibilite experiências interdisciplinares como a complexidade da busca de soluçóes que exige" (Porto, 1998 apud FEREIRA e ANJO, 2001).

Segundo Peres (2002), a saúde coletiva é um movimento que surgiu por volta dos anos 70 e que veio "contestando os atuais paradigmas de saúde existentes na América Latina e buscando uma forma de superar a crise no campo da saúde". Para Winslow-Terris a definiçâo de saúde pública parte do princípio de que é "a arte e a ciência de prevenir a doença e a incapacidade, prolongar a vida e promover a saúde física e mental mediante os esforços organizados da comunidade" (TERRIS; PAIM p.12 apud Peres, 2001).

Assim, danos no meio ambiente influem diretamente na saúde coletiva. É o exemplo dos danos causados pela destinaçâo incorreta dos resíduos sólidos urbanos em lixōes a céu aberto, sem qualquer tratamento.

Os efeitos na saúde humana e no meio ambiente de agentes físicos, químicos e biológicos sâo infinitos e podem comprometer toda a coletividade. Estudo realizado por Ferreira e Anjo (2001) apontou alguns destes agentes, conforme a seguir:

- Agentes físicos: o odor emanando dos resíduos pode causar mal - estar, cefaleias e náuseas em trabalhadores e pessoas que se encontrem proximamente a equipamentos de coleta ou de sistemas de manuseio, transporte e destinaçăo final.

- Agentes químicos: nos resíduos sólidos municipais pode ser encontrada uma variedade muito grande de resíduos químicos, dentre os quais merecem destaque pela presença mais constante: pilhas e baterias, óleos e graxas, pesticidas, herbicidas, solventes, tintas, produtos de limpeza, cosméticos, remédios e aerossóis. Destaque que uma grande parcela destes resíduos é classificada como perigosa e pode ter efeitos deletérios à saúde humana e ao meio ambiente. 
- Agentes biológicos: estes estăo presentes nos resíduos sólidos e podem ser responsáveis pela transmissáo direta e indireta de doenças. Os micro-organismos patogênicos ocorrem nos resíduos sólidos municipais mediante a presença de lenços de papel, curativos, fraldas descartáveis, papel higiênico, absorventes, agulhas e seringas descartáveis e camisinhas, originadas da populaçăo; dos resíduos de pequenas clínicas, farmácias e laboratórios e, na maioria dos casos, dos resíduos hospitalares, misturados aos resíduos domiciliares (Kenedy, 1992; Ferreira, 1997 apud FERREIRA e ANJO, 2001, p.692).

Destaca-se que muitos destes agentes săo transmissores de doenças, e as pessoas mais vulneráveis a elas, săo as que primeiramente estâo em contato direto, como os catadores de lixo, e segundo as que residem nas proximidades.

\subsection{RESÍDUOS SÓLIDOS URBANOS}

Recentemente foi publicado no site de notícias UOL (2016), que em 2030, a metade de toda populaçăo mundial poderá ter dificuldades para obter água. Esta notícia traz dois pontos de reflexâo, sendo a primeira a intensa preocupaçấo com o meio ambiente e a sobrevivência da espécie humana. Outro ponto é com relaçaáo ao crescimento populacional e a falta de destinaçấo correta dos resíduos sólidos produzidos por todos.

De acordo com a Lei Federal n . 12.305/2010, os resíduos sólidos consistem em:

XVI - resíduos sólidos: material, substância, objeto ou bem descartado resultante de atividades humanas em sociedade, a cuja destinaçăo final se procede, se propôe proceder ou se está obrigado a proceder, nos estados sólido ou semissólido, bem como gases contidos em recipientes e líquidos cujas particularidades tornem inviável o seu lançamento na rede pública de esgotos ou em corpos d'água, ou exijam para isso soluçóes técnica ou economicamente inviáveis em face da melhor tecnologia disponível; (BRASIL, 2010).

Segundo a Norma Brasileira NBR 10004/1987 apud (ALMEIDA, 2009, p.55), os resíduos sólidos săo:

aqueles resíduos nos estados sólido e semissólido, que resultam de atividades da comunidade de origem industrial, doméstica, hospitalar, comercial, agrícola, de serviços e de varriçăo. Ficam incluídos nesta definiçăo os lodos provenientes de sistemas de tratamento de água, aqueles gerados em equipamentos e instalaçóes de controle de poluiçáo, bem como determinados líquidos cujas particularidades tornem inviável o seu lançamento na rede pública de esgotos ou corpos de água, ou exijam para isso soluçōes técnicas e economicamente inviáveis em face a melhor tecnologia disponível

No mundo săo produzidos aproximadamente 63 milhóes de toneladas de lixo no ano (SILVA, 2014). E segundo PNUMA (Programa das Naçóes Unidas para o Meio Ambiente) até em 2025, o lixo mundial deve aumentar em 1,3 bilhóes de toneladas para 2,2 bilhóes de toneladas. Destaca ainda que "a gestăo dos resíduos e o descarte correto de materiais se torna cada dia mais imprescindível para que o mundo caminhe para um desenvolvimento sustentável".

A questăo preocupante diz respeito aos locais onde será destinada tamanha quantidade de resíduos sólidos, tendo em vista que os lixóes a céu aberto já nâo comporta mais. Segundo Silva (2014, p. 135) os lixōes vêm causando danos irreversíveis ao meio 
ambiente, e "em cosequencia dessa prática irracional os impactos ambientais negativos podem ocasionar a contaminaçâo de corpos d'água, assoreamento, enchentes, proliferaçăo de vetores (macros e micros) transmissores de doenças, além da poluiçâo visual, mau cheiro [...]".

Para tanto, é necessário realizar um estudo nas comunidades que residem próximas ao lixăo e verificar quais sâo as suas percepçōes e condiçōes se a gestăo dos resíduos sólidos está contribuindo para uma melhora na saúde coletiva.

\section{COLETA DE DADOS}

A coleta de dados do presente estudo baseou-se na realizaçăo de entrevista semiestruturada com moradores dos bairros, que fica próximo ao local onde sâo despejados os lixos produzidos diariamente pela populaçăo de Porto Murtinho - MS.

A escolha da técnica de entrevista para coleta de dados procedeu devido à abrangência de fatos e fenômenos que possam ser levantadas. Na regiăo estudada há pessoas que apresentam dificuldades para ler e escrever. Assim outro instrumento, como o questionário, prejudicaria a coleta de dados do presente estudo.

No mapeamento da populaçâo alvo da pesquisa, denominou-se a regiăo leste da cidade, abrangendo assim, o final do bairro Salim Cafure e chácaras da regiâo. Todavia, năo foi possível mapear o universo da pesquisa desta regiăo da cidade, assim delimitando somente os moradores residentes próximos ao lixăo, conforme figura abaixo.

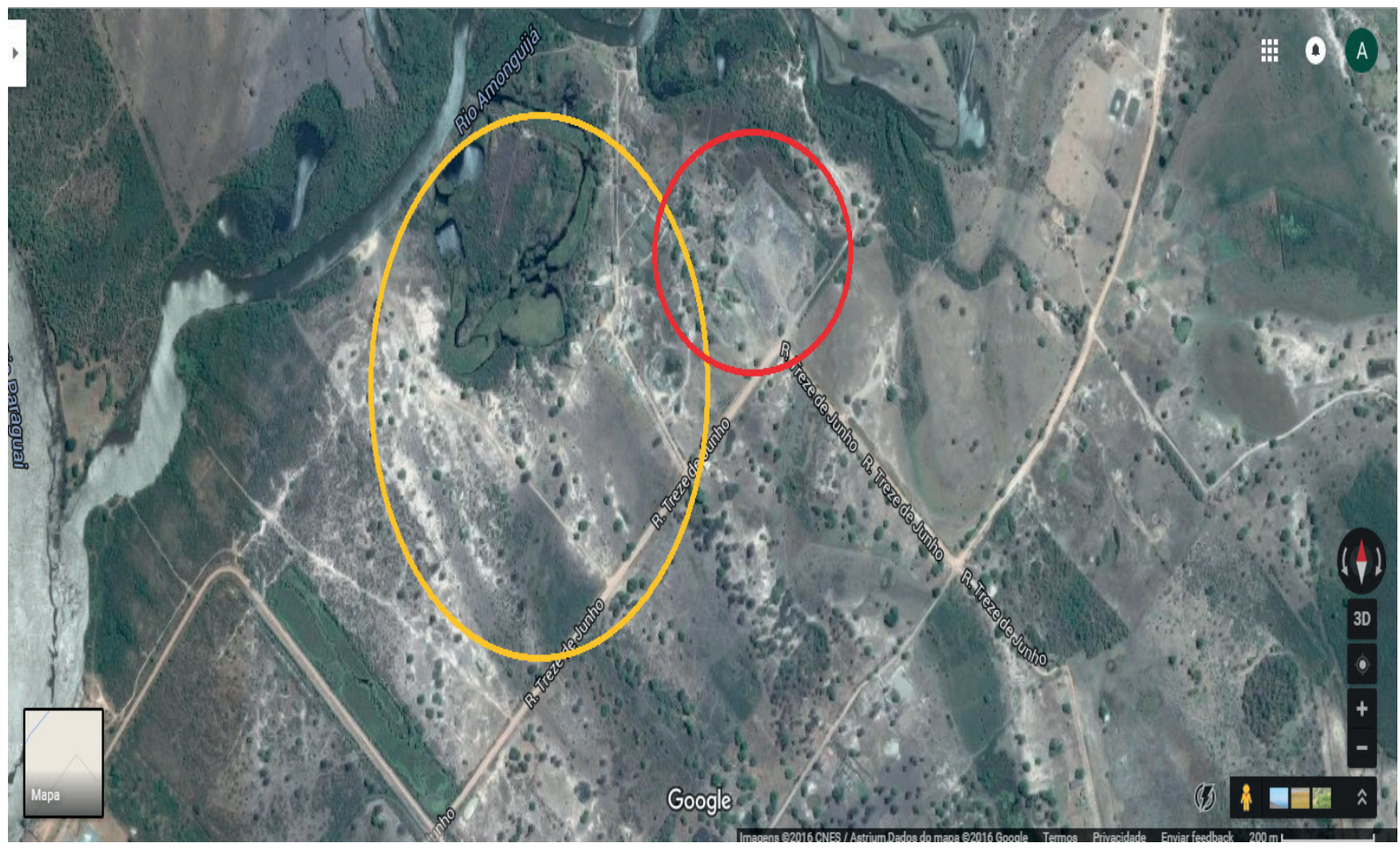

Figura 1. Regiăo denominada "Matadouro" no Município de Porto Murtinho - MS Fonte: Google Maps (2016) 
Na demarcaçăo em amarelo, fica a regiâo denominada "Matadouro", que se encontra próximo à foz do rio Amonguijá e também na baixa bacia do Rio Amonguijá. Esta regiăo localiza-se na sub-regiăo do Pantanal de Porto Murtinho (SILVA, 2015 apud ABDON, 1998).

Este local é conhecido devido ao passado abrigar um abatedouro municipal de bovinos. Segundo Silva (2015, p. 93) este local possui uma infraestrutura "precária e fica ao lado do destino final dos resíduos sólidos urbanos - lixăo a céu aberto". Na imagem acima, o lixâo municipal foi circulado em vermelho.

Ainda de acordo com estudos realizados por Silva (2015, p. 104) "neste núcleo urbano moram 34 famílias, cerca de 130 pessoas, residindo em 16 casas de material aproveitado, 16 de madeira e 2 de tijolo". As maiorias săo do sexo masculino, ou seja, 83 e em sua maioria 82, alfabetizados. Assim, o tipo da amostra da presente pesquisa é a năo probabilística e caracterizada, como intencional, pois os "elementos da populaçáo que fornecerăo os dados para a pesquisa sâo selecionados intencionalmente pelo pesquisador" (ALMEIDA, 2011, p. 22). Desta forma, foram selecionados 10 (dez) moradores do local para a realizaçăo da entrevista.

\section{DISCUSSÃO DOS RESULTADOS}

\section{1. $O$ LIXĀO E A REGIẢO DO MATADOURO NO MUNICÍPIO DE PORTO MURTINHO - MS}

O Município de Porto Murtinho está localizado na regiăo sudoeste do Estado de Mato Grosso do Sul, que segundo o IBGE (2010) possui populaçâo de aproximadamente 15.372 habitantes. Sua economia é voltada para a pecuária, com grandes propriedades rurais distribuídas por todo o território do município.

Um ponto que iguala a cidade de Porto Murtinho com outros municípios do Brasil é a ausência de um local apropriado para a disposiçăo dos seus resíduos sólidos urbanos, conforme exige a Lei Federal n. 12.305/2010. De acordo com Silva (2014) “Na verdade pouco se avançou e o país destina inadequadamente 17,8\% das 63 milhōes de toneladas de lixo produzidas anualmente".

Esta prática de destinaçâo final dos resíduos sólidos a céu aberto foi proibida no dia 03 de Agosto de 2014, sendo ainda um grande problema para vários municípios, dentre eles Porto Murtinho. No mesmo ano de proibiçăo, o Ministério Público Estadual de Mato Grosso do Sul, por meio da Comarca de Porto Murtinho firmou um TAC (Termo de Ajustamento de Conduta) para que proíba a entrada de pessoas no lixăo.

Segundo Silva (2014) o "năo cumprimento do acordo pode gerar uma multa de pelo menos 50 milhôes de reais devido ao fato de que o lixo causa impactos negativos ao meio ambiente, como margens de ruas e leito de rios e/ou mananciais de abastecimento".

Ainda no tocante a saúde coletiva, a disposiçăo incorreta do lixo pode provocar diversas doenças, como afirma Ferreira e Anjos (2001, p.43): 
Os impactos provocados pelos resíduos sólidos municipais podem estender-se para a populaçáo em geral, por meio da poluiçăo e contaminaçáo dos corpos d'água e dos lençóis subterrâneos, direta ou indiretamente, dependendo do uso da água e da absorçăo de material tóxico ou contaminado.

Além destes problemas que os lixôes a céu aberto causam, tem o risco de contaminaçâo pela carne de animais criados próximos aos vazadouros e que podem causar a transmissăo de doenças ao ser humano (FERREIRA e ANJO, 2001).

Na regiâo do lixăo de Porto Murtinho, quando chove, há o alagamento das áreas, fazendo com que o Chorume caia no Rio Amonguijá. A figura 2.a montra o lixăo após chuva e a figura 2.b mostra o Chorume produzido.

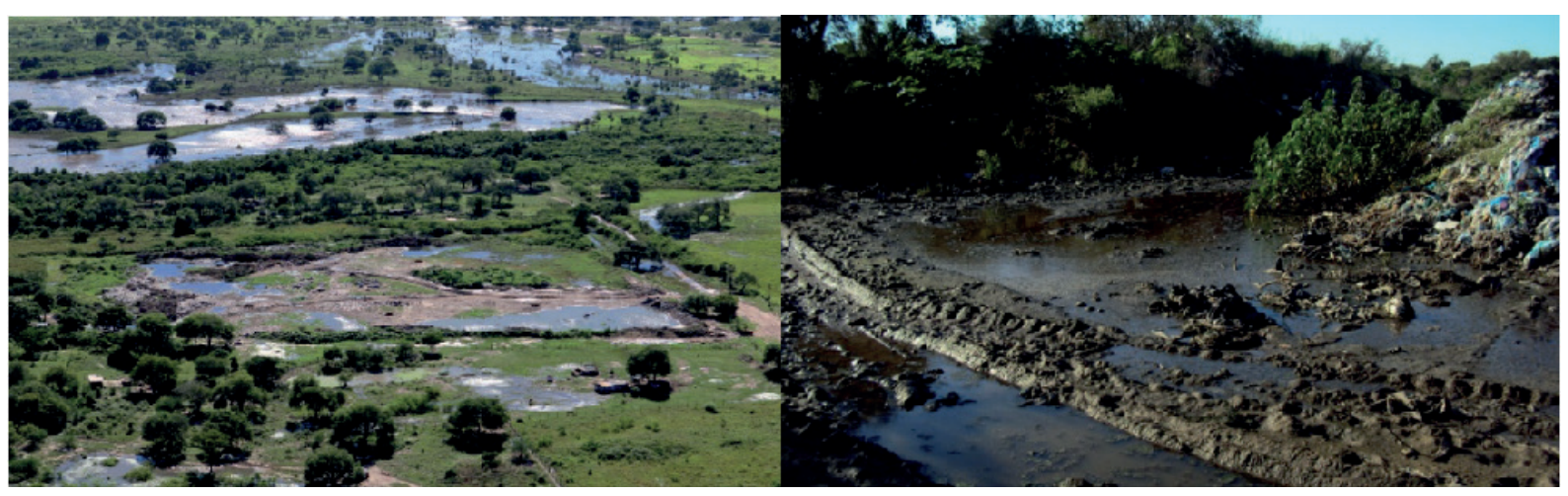

(a)

(b)

Figura 2.a - Vista aérea do lixăo municipal após chuva, b - Chorume empoçado no lixăo Municipal

Fonte: Silva (2014).

Segundo Silva (2010, p. 131) “O perigo de contaminaçăo do manancial, pelo chorume empoçado, pode repercutir direta ou indiretamente nos rios abaixo da Baixa Bacia do Amonguija". Há também uma pequena comunidade que reside nas regiōes bem próximas do lixăo, denominada de "Matadouro", objeto este do nosso estudo.

A regiáo do matadouro constituiu um novo bairro para Porto Murtinho. Sua paisagem nâo é das melhores, segundo Silva (2015, p. 93) “Possui uma concentraçăo urbana, antiga vila do Matadouro Municipal, com precária infraestrutura e fica ao lado do destino final dos resíduos sólidos urbanos - Lixăo a céu aberto". Nas imagens abaixo é possível à regiáo do matadouro, com entulhos, casas construídas com sobras de materiais e lixo, residências e esgoto na rua. 


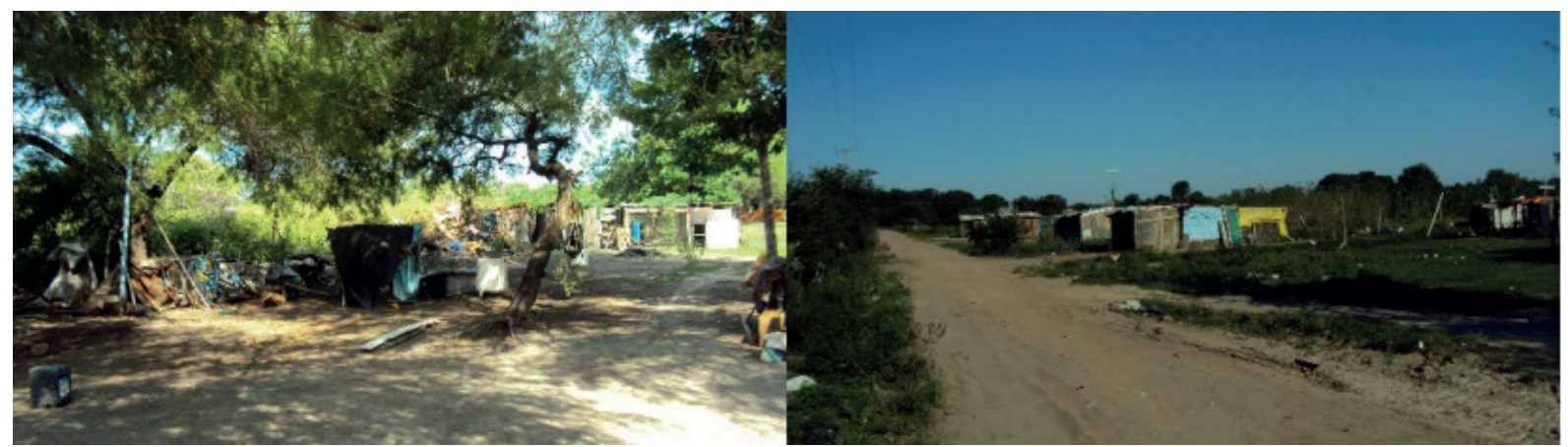

Figura 3. Regiăo do matadouro em Porto Murtinho - MS

Fonte: Silva, R.P. (2014).

É evidente a importância de se estudar e compreender a percepçâo dos moradores daquela regiăo, sobre a gestăo dos resíduos sólidos e sua contribuiçăo para a saúde coletiva. Assim, procedeu-se com as entrevistas no período de 14 de Março de 2016 a 18 de Março de 2016, selecionando 10 moradores, ou seja, 7,69\% da populaçăo alvo. Năo houve qualquer restriçăo para a realizaçăo das entrevistas, havendo colaboraçăo entre todos os moradores.

O perfil dos moradores entrevistados constituiu na sua maioria homens, de idade entre 30 a 55 anos de idade, com nível de escolaridade alfabetizado, entre primeira ao oitavo ano do ensino fundamental. Năo houve dentro da amostra, pessoa com nível médio ou superior.

A percepçáo dos moradores daquela regiâo com relaçâo ao local onde estăo sendo despejados os resíduos sólidos é totalmente desfavorável, no sentido de que ele (lixăo) deve ser transferido para outra parte do território de Porto Murtinho - MS.

Já houve estudos realizados nesse sentido, pelo Prof. Rodrigo Pereira da Silva (2014), denominado de "O uso da geotecnologia na escolha de área adequada para a implantaçâo de aterro sanitário", que colabora com as percepçóes dos moradores do Matadouro. A conclusăo do estudo foi de que devem adotar critérios, sendo "é preciso uma adaptaçáo para a realidade local que implica na incorporaçăo de uma nova área restritiva relacionada às áreas úmidas, cujo critério eliminará da análise áreas com presença de umidade".

O local onde será construído um futuro aterro sanitário, deverá obedecer a critérios, para que năo se crie novamente outro lixăo avançado na zona urbana, continuando com a degradaçâo do meio ambiente, ou seja, muda-se apenas o problema de lugar.

No matadouro, devido ao que a maioria das residências serem construídas de materiais reciclados, a questâo do saneamento básico é precária. As fezes e urinas săo destinadas em fossas construídas próximas as suas residências, e a destinaçâo final dos resíduos sólidos, todos os entrevistados responderam que realizam a queima no final do dia.

A coleta de lixo náo chega ao bairro, sendo obrigado conforme depoimentos dos entrevistados a efetuarem a queima. Dos 10 entrevistados, 8 responderam que aproveitam os materiais reciclados, ou vendem para cooperativas ambulantes que passam com seus caminhóes pela cidades em tempos e tempos. 
No tocante a saúde coletiva dos moradores, quando perguntado se os mesmos fervem a água para beber ou utiliza outros meios de filtragem ou água mineral, 90\% responderam que nâo realizam qualquer meio de filtragem. Apenas 10\% da amostra manifestaram que năo dispóe de água potável fornecido pela concessionária, sendo utilizada água de poços artesanais.

Sob as doenças decorrentes da má gestăo de resíduos sólidos, 60\% dos entrevistados apontaram que já contraíram diarreias. Năo houve casos de doenças como Hepatite B. Os dados coletados na entrevista colaboram com o estudo de Silva (2015), em que as doenças encontradas foram hanseníase, hipertensăo e diabetes. Nâo há correlaçâo entre as doenças e situaçâo degradante e insalubre do local.

Corrobora Lombardo (1985 apud SILVA, 2015) “Por tais condiçôes, pode ser identificado um crescimento urbano em local impróprio, sem critérios e respaldo técnico que comprometerâo o futuro da populaçáo dessa área". Assim, percebe que o crescimento desacelerado e sem planejamento dessa área pode agravar a situaçáo da saúde coletiva, bem como danos ao meio ambiente.

\section{CONSIDERAÇÕES FINAIS}

Ao finalizar estudo sobre a gestăo dos resíduos sólidos urbanos e suas contribuiçóes com a saúde coletiva, mais uma vez afirmou a importância de cuidar e preservar o meio ambiente. $O$ presente estudo, tendo como estudo de caso a regiâo do matadouro em Porto Murtinho partiu do seguinte problema: a atual gestâo de resíduos sólidos urbanos do Município de Porto Murtinho - MS contribui com a saúde coletiva de sua populaçăo residente próxima ao lixăo?

A partir dos relatos dos moradores entrevistados, foram observados que há ainda muito que fazer para minimizar os impactos causados no meio ambiente. Percebeu que a saúde coletiva é totalmente influenciada, quando năo há qualquer disposiçăo efetiva na gestăo dos resíduos sólidos. Assim, no Bairro Matadouro "a cada dia é acarretado alteraçôes significativas ao meio ambiente, alterando a particularidade de alguns suprimentos de vital importância ao ser humano, tais como ar fresco, água potável, alimento, espaços de lazer, vegetaçăo nativa, dentre outros. Além de ser um local insalubre localiza-se ao lado de um lixăo" (SILVA, 2015).

Ficou evidenciado que os moradores nâo percebem a presença do poder público na promoçấo da saúde coletiva e meio ambiente, pois o local ainda continua sendo tratado como abandono e descaso. O lixăo que fica próximo à regiấo do matadouro continua recebendo diariamente toneladas e mais toneladas de lixos, sem que haja uma soluçáo para o problema.

Para próximas pesquisas sugere-se que sejam feitos estudos sobre a viabilidade técnica e econômica - financeira de um consórcio, na implantaçăo de um aterro sanitário entre os municípios da regiâo, que fazem fronteira com o Município de Porto Murtinho - MS. 


\section{REFERÊNCIAS}

ALMEIDA, P.S. de. Resíduos sólidos urbanos: aterro sustentável para municípios de pequeno porte. Sociedade, Meio Ambiente e Cidadania. USP, Săo Paulo, 2009.

BOAVENTURA, E.M. Metodologia da pesquisa: monografia, dissertação e tese. 1.ed. - Săo Paulo: Atlas, 2012.

BRASIL, Constituiçâo Federal de 1.988. Disponível em <http://www.planalto.gov.br/ ccivil_03/constituicao/ConstituicaoCompilado.htm>Acesso em 27 de Janeiro de 2016.

FERREIRA, J.A; ANJOS, L.A. Aspectos da saúde coletiva e ocupacional associados à gestăo dos resíduos sólidos municipais. Cad. Saúde Pública, Rio de Janeiro, 17, p. 689-696, mai-jun, 2001.

BRASIL, Planos Municipais de Gestāo Integrada de Resíduos Sólidos. Disponível em <http://www.mma.gov.br/cidades-sustentaveis/residuos-solidos/instrumentos-da-politica-de-residuos/planos-municipais-de-gest\%C3\%A3o-integrada-de-res\%C3\%ADduos-s\%C3\%B3lidos>. Acesso em 08 de Mar de 2016.

PNUMA, Programa das Naçóes Unidas para o Meio Ambiente. Disponível em <http://web. unep.org/regions/brazil/> Acesso em 25 de Mar de 2016.

PERES, Laerte A. A saúde e a saúde coletiva. Disponível em <http://www.hospvirt.org.br/ enfermagem/port/scol_int.html> Acesso em 25 de Mar de 2016.

SECRETARIA MUNICIPAL DE ASSISTÊNCIA SOCIAL, Porto Murtinho - MS, 2014.

SILVA, R.P. O uso da geotecnologia na escolha de áreas adequadas para implantaçăo de aterro sanitário. Anais $5^{\circ}$ Simpósio de Geotecnologias no Pantanal, Campo Grande - MS, 22 a 26 de Nov. de 2014.

SILVA, R.P. Caracterizaçâo da situação das áreas de risco a inundaçāo e alagamento no entorno do dique da cidade de Porto Murtinho - MS. Dissertaçăo de Mestrado. Universidade Federal de Mato Grosso do Sul, 2015.

SIQUEIRA, M.M; MORAES, M.S. Saúde coletiva, resíduos sólidos urbanos e os catadores de lixo. Ciência \& Saúde Coletiva. p. 2115-2122, 2009.

UOL. Notícias. Disponível em <http://noticias.uol.com.br/meio-ambiente/ultimas-noticias/redacao/2016/03/22/metade-da-populacao-mundial-podera-ter-dificuldades-para-obter-agua-em-2030.htm> . Acesso em 24 de Mar de 2016. 